\title{
Influence of the methods of estimation of the wind velocity distribution parameters on the accuracy of wind energy calculations
}

\author{
T. Niedoba ${ }^{1} \&$ B. Soliński ${ }^{2}$ \\ ${ }^{1}$ Faculty of Mining and Geoengineering, \\ University of Science and Technology in Krakow, Poland \\ ${ }^{2}$ Faculty of Management, \\ University of Science and Technology in Krakow, Poland
}

\begin{abstract}
Many parameters influence wind energy resources, as well as the amount of energy that can be produced by wind power plants. They are connected with wind and climatic conditions, the location of the power plant, as well as those associated with the power plant itself.

The basic parameter of wind energy is the velocity of flowing air, whose variation is very high. As a result, permanent changes in power and wind energy amounts occur, which was shown in the paper on the basis of selected locations in Poland and Netherlands.

The methodology of "Wind Atlas", elaborated by RISO in 1989 and being currently the world standard, is used to evaluate wind energy resources. In this methodology, the Weibull distribution function is applied to describe the distribution of wind velocity, whose parameters are calculated on the basis of empiric data, with the moments method as the method of approximation. This is, however, a possible source of errors, which are then included in the produced amount of energy. It is crucial, then, to apply the proper approximation methods and to know the possible occurring errors.

The measurement of the wind velocity should be very precise, because even a small error like $5 \%$ in evaluation of wind velocity produces about a $16 \%$ miscalculation in the forecasting of the total amount of energy produced.

Three methods of Weibull distribution function approximation for wind velocity were presented in the paper: the least square method, the maximum likelihood method and the moments method. The given results were verified and
\end{abstract}


the impact of the applied approximation methods on the preciseness of the produced wind velocity distribution function, as well its statistical parameters and energetic resources, was evaluated.

Keywords: wind velocity, Weibull distribution function, approximation methods, wind energy.

\section{Introduction}

Many parameters have an influence on the quantity of wind energy resources and the amount of achievable energy obtained by wind power plants. They are connected with both wind, climatic and landscape conditions, as well the parameters of the wind power plant itself.

The basic parameter of wind energy is air flow velocity and its influence directly on wind energy resources. The characteristic feature of air flow is continuous changeability - noticeable in a whole spectrum of a time period which is connected with continuous wind power and energy changes. The methodology of "Wind Atlas" is being applied to evaluate energy resources, which was established by RISO in 1989 [1-4] and is currently the world standard. This methodology assumes the Weibull distribution function in purpose of wind velocity occurring distribution function in certain areas description and the parameters of this distribution function are given on basis of empirical data, applying the moment method as the approximation method. However, this approximation is a source of numerous errors, which are then transformed into given energy amounts. Thus, for the purpose of more precise determination of energy resources it is imperative to apply correct approximation methods and to be aware of the possible occurring errors.

\section{Dependence of quantity of created energy on wind velocity}

The significant dependence of wind energy on air flow velocity is the reason that the wind velocity measurement should be more precise, because even a very small error, e.g. of $5 \%$ in wind velocity evaluation, can result in a $16 \%$ error in the forecasted energy evaluation. This is caused by the fact that the amount of energy is growing proportionally to the cube of wind velocity (1), e.g. if wind velocity grows twice then the energy produced grows eight times. The basics of wind energy calculation were widely described in $[2,5-8]$.

$$
E=\frac{1}{2} \rho v^{3} t \cdot\left(\mathrm{Wh} / \mathrm{m}^{2}\right)
$$

where: $\rho$ - air density $\left(\mathrm{kg} / \mathrm{m}^{3}\right) ; v$ - wind velocity $(\mathrm{m} / \mathrm{s}) ; t$ - time.

It is possible to notice that on figure 1 , presenting the wind power in dependence on its velocity for air density $\rho=1,25 \mathrm{~kg} / \mathrm{m}^{3}$ (line A). For velocity of $6 \mathrm{~m} / \mathrm{s}$ the wind achieves the power of $135 \mathrm{~W} / \mathrm{m}^{2}$, and for the velocity twice higher, of $12 \mathrm{~m} / \mathrm{s}$, the given power is eight times higher, which would achieve $1080 \mathrm{~W} / \mathrm{m}^{2}$. Assuming that the wind velocity is stable in time equal to $t$ (e.g. $t=1$ 


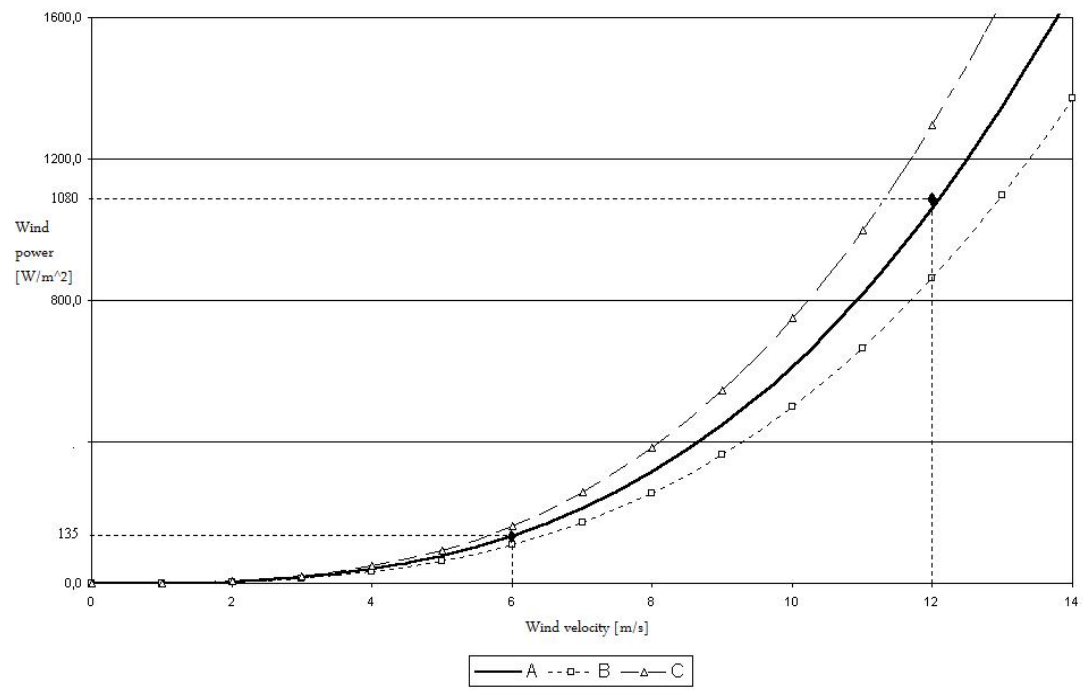

Figure 1: Theoretical wind power in dependence on air velocity and air density. Source: [5].

hour), then the produced energy will be equal to, respectively, $0,135 \mathrm{kWh} / \mathrm{m}^{2}$ and $1,08 \mathrm{kWh} / \mathrm{m}^{2}$. From this relationship it is clearly visible that the locations characterized by higher wind velocities are more profitable.

\section{Wind velocity distribution function}

Wind velocity is not a stable value and is changing continuously. Generally, every moment the wind velocity varies. This changeability is a characteristic

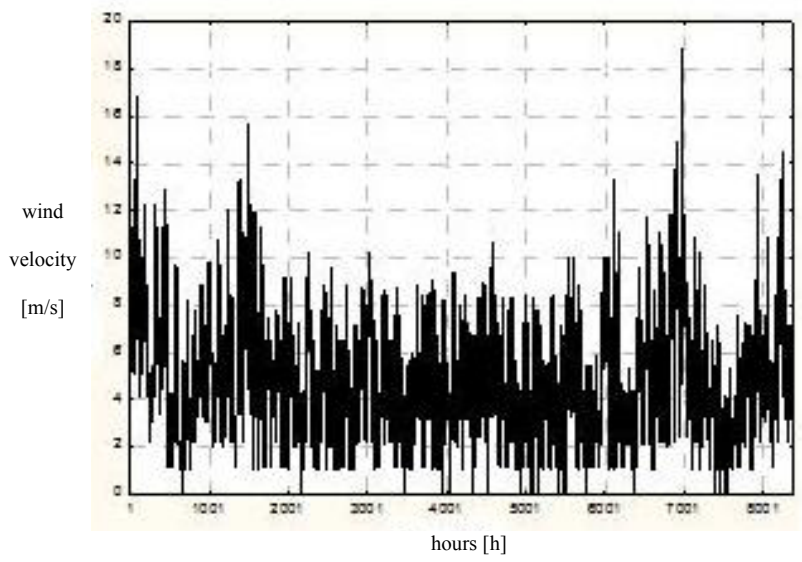

Figure 2: Hourly changeability of wind velocity during one year in the area of Rymanow. Source: personal elaboration. 


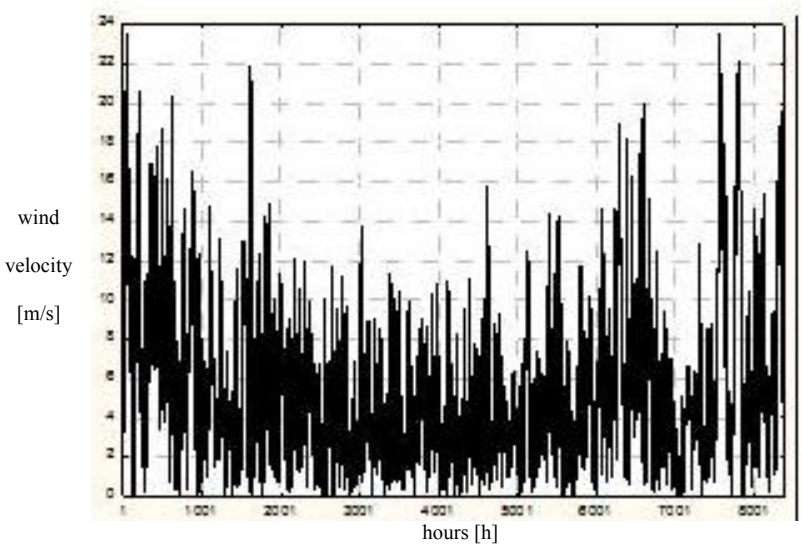

Figure 3: Hourly changeability of wind velocity during one year in the area of Lelystad. Source: personal elaboration.

feature of flowing air, which is also very clear when averaging data. For hour averaging - the standard being applied to determine wind energy resources (currently also 10 minutes averaging is being applied) - this changeability was shown on figures 2 and 3 for selected two locations in Poland and Netherlands. On reviewing this data it is possible to notice the continuous fluctuation of mean hour wind velocity.

Variation of wind velocity influences on amount of obtained energy, so it is very crucial to collect precise data by high quality anemometers and data loggers what is the subject of many scientific works [2, 5, 7, 9-11].

As a result of taking into consideration such a big variation in wind velocity during the following time units, it is advisable to apply the probabilistic distribution function to evaluate wind energy resources. The distribution function being applied in wind energy is a two-parametric Weibull distribution function, which is described by a scale parameter $A$ and shape parameter $k$. The formulae (2) of Weibull density function, in which $f(v)$ is frequency of occurring wind velocity during certain period of time, is in the following form [5-7, 11,12]:

$$
f(v)=\frac{k}{A}\left(\frac{v}{A}\right)^{k-1} \exp \left[-\left(\frac{v}{A}\right)^{k}\right]
$$

and the distribution function of random variable $v$ of Weibull distribution function is determined by the equation (3).

$$
F(v)=1-\exp \left[-\left(\frac{v}{A}\right)^{k}\right]
$$

Parameters $A$ and $k$ influence the distribution of a random variable, as well as on the form of the density curve, and determine the characteristics of the wind velocity and thus its frequency distribution. It is crucial then to operate by the correct parameters given by approximation. Otherwise, each inaccuracy will be 
magnified to an even bigger inaccuracy of energy evaluation (according to formulae 1).

\section{Approximation methods}

As a result of approximating the unknown distribution function of the researched random variable, it is advisable to apply one of several available approximation techniques. The most frequent methods being applied are: the least square method, the maximum likelihood method and the moments method.

\subsection{Least squared method (LSM)}

Let assume that $(\mathrm{X}, \mathrm{Y})$ are random variables and $\operatorname{set}\left\{\left(x_{1}, y_{1}\right) \ldots,\left(x_{n}, y_{n}\right)\right\}$ is a random sample. If between variables $\mathrm{X}$ and $\mathrm{Y}$ functional dependence occurs $Y=\Phi\left(X ; \Theta_{1}, \ldots, \Theta_{k}\right)$, where $\Theta_{1}, \ldots, \Theta_{k}$ are unknown parameters, then we may assume point $\left(\hat{\Theta}_{1}, \hat{\Theta}_{2}, \ldots, \hat{\Theta}_{k}\right)$ as the evaluation of these parameters, which minimize the function.

$$
L\left(\Theta_{1}, \Theta_{2}, \ldots, \Theta_{k}\right)=\sum_{i=1}^{n}\left(y_{i}-\Phi\left(x_{i} ; \Theta_{1}, \ldots, \Theta_{k}\right)\right)^{2} .
$$

If function $\Phi$ is a differential in relation to variables $\Theta_{1}, \ldots, \Theta_{k}$ then to determine point $\left(\hat{\Theta}_{1}, \ldots, \hat{\Theta}_{k}\right)$ the following set of equations has to be solved:

$$
\frac{\partial L}{\partial \Theta_{j}}\left(\hat{\Theta}_{1}, \ldots, \hat{\Theta}_{k}\right)=0 \quad j=1, \ldots, k
$$

If $Y=\Phi\left(X, \Theta_{1}, \Theta_{2}\right)$ then, if it is possible, the new variables $\tilde{x}$ and $\tilde{y}$ are being introduced to create the dependence between new variables as linear, so $\tilde{y}=a \tilde{x}+b$, where coefficients $a=a\left(\Theta_{1}, \Theta_{2}\right), b=b\left(\Theta_{1}, \Theta_{2}\right)$ are being determined as linear regression coefficients and then the parameters $\Theta_{1}$ and $\Theta_{2}$ are determined by reverse transformation [13].

\subsection{Maximum likelihood method (MLM)}

Let assume that $X$ is a random variable and that the density function of this variable $f\left(x, \Theta_{1}, \ldots, \Theta_{k}\right)$ is known, where $\Theta_{1}, \Theta_{2}, \ldots, \Theta_{k}$ are unknown parameters. Let $\left(x_{1}, \ldots, x_{n}\right)$ be $n$-dimensional random sample for variable $X$.

The likelihood function is the function given by equation (6).

$$
\begin{aligned}
& \mathrm{L}\left(\Theta_{1}, \ldots, \Theta_{\mathrm{k}}\right)=\mathrm{f}\left(\mathrm{x}_{1} ; \Theta_{1}, \ldots, \Theta_{\mathrm{k}}\right) \cdot \mathrm{f}\left(\mathrm{x}_{2} ; \Theta_{1}, \ldots, \Theta_{\mathrm{k}}\right) \cdot \ldots \\
& \cdot \mathrm{f}\left(\mathrm{x}_{\mathrm{k}} ; \Theta_{1}, \ldots, \Theta_{\mathrm{k}}\right)
\end{aligned}
$$

In purpose of determination of unknown parameters values $\Theta_{1}, \Theta_{2}, \ldots, \Theta_{k}$ the point $\left(\hat{\Theta}_{1}, \ldots, \hat{\Theta}_{k}\right)$ is selected, for which function $\ln L\left(\Theta_{1}, \ldots, \Theta_{k}\right)$ achieves the maximum. It means that in point $\left(\hat{\Theta}_{1}, \ldots, \hat{\Theta}_{k}\right)$ the set of equation $(7)$ is satisfied. 


$$
\frac{\partial f}{\partial \Theta_{j}}\left(\hat{\Theta}_{1}, \ldots, \hat{\Theta}_{k}\right)=0 \quad \text { for } \quad j=1, \ldots, k
$$

By solving this set of equations, the estimators of the unknown distribution function parameters are given by maximum likelihood method [13].

\subsection{Moments method (MM)}

If $\left(x_{1}, \ldots, x_{n}\right)$ is a big random sample then random variable $X$ is variable, which distribution function, which depends on parameters $\left(\Theta_{1}, \ldots, \Theta_{n}\right)$. The moments method consists in assuming the solution of set of equations, which is given by equating individual moments from sample with theoretical moments, as the evaluation of parameters $\Theta_{1}, \ldots, \Theta_{n}$, so:

$$
\frac{1}{n} \sum_{i=1}^{n} x_{i}^{2}=m_{l}\left(\Theta_{1}, \ldots, \Theta_{k}\right) \text { for } l=1, \ldots, k \text {. }
$$

where $m_{l}\left(\Theta_{1}, \ldots, \Theta_{k}\right)=\int_{-\infty}^{+\infty} x^{l} f\left(x ; \Theta_{1}, \ldots, \Theta_{k}\right) d x$, and $f\left(x ; \Theta_{1}, \ldots, \Theta_{k}\right)$ is density of random variable $X$ density function. The moments method may be applied where we have the analytic form of moments $m_{l}\left(\Theta_{1}, \ldots, \Theta_{k}\right)[14]$.

\section{Approximation of the wind velocity distribution function}

The methods mentioned above were applied to an approximation done on the basis of empirical data originating from Rymanow (Poland) - data concerning a period in 1998, collected by the Laboratory of Wind Energy Monitoring AGH (www.wiatr.krakow.pl) and data from Lelystad (Netherlands) - data relating to a period in the year 1998, originating from researches KNMI (table 1). This data was selected partially, because it lacked some measurements, in way ensuring to have pairs of data for every hour both from location of Rymanow, as well from location of Lelystad. In this way, the 2 sets containing 8363 measurements each were given, which in turn gave the coefficient of data availability equal to $96 \%$.

Table 1: Characteristics of empirical data concerning wind velocity.

\begin{tabular}{|c|c|c|c|c|c|c|c|}
\hline Data & $\begin{array}{c}\text { Height of } \\
\text { measurement } \\
{[\mathrm{m} \text { n.p.g }]}\end{array}$ & $\begin{array}{c}\text { Averagi } \\
\text { ng time }\end{array}$ & $\begin{array}{c}\text { Mean } \\
\text { value } \\
{[\mathrm{m} / \mathrm{s}]}\end{array}$ & $\begin{array}{c}\text { Standard } \\
\text { deviation } \\
{[\mathrm{m} / \mathrm{s}]}\end{array}$ & $\begin{array}{c}\text { Minimum } \\
{[\mathrm{m} / \mathrm{s}]}\end{array}$ & $\begin{array}{c}\text { Maximum } \\
{[\mathrm{m} / \mathrm{s}]}\end{array}$ \\
\hline $\begin{array}{c}\text { Rymanow } \\
1998 \\
\text { POLAND }\end{array}$ & 20 & $1 \mathrm{~h}$ & 8363 & 5,591 & 4,081 & 0,0 & 23,6 \\
\hline $\begin{array}{c}\text { Lelystad } \\
1998\end{array}$ & 10 & $1 \mathrm{~h}$ & 8363 & 4,850 & 2,545 & 0,0 & 18,9 \\
$\begin{array}{c}\text { NETHER } \\
\text { LANDS }\end{array}$ & & & & & & \\
\hline
\end{tabular}

Source: personal elaboration. 
As a result of the application of the approximation methods mentioned above, the Weibull distribution function parameters were given, which are presented in table 2. Furthermore, the appropriateness of given function was evaluated by residual deviation given by formulae (9).

$$
s_{r}=\sqrt{\frac{\sum_{i=1}^{k}\left[F\left(v_{i}\right)-\hat{F}\left(v_{i}\right)\right]^{2}}{n-2}}
$$

where: $F\left(v_{i}\right)$ - theoretical distribution function; $\hat{F}\left(v_{i}\right)$ - empirical distribution function, $n$ - set number.

Table 2: $\quad$ Results of the wind velocity distribution function approximation.

\begin{tabular}{|c|c|c|c|c|}
\hline Data & Parameters/statistics & MLM & LSM & MM \\
\hline \multirow{4}{*}{$\begin{array}{c}\text { Rymanow 1998 } \\
\text { Poland }\end{array}$} & $A$ & 6,153 & 6,119 & 6,00 \\
\cline { 2 - 5 } & $k$ & 1,414 & 1,368 & 1,33 \\
\cline { 2 - 5 } & Residual deviation $s_{r}[\%]$ & 0,204 & 0,199 & 0,202 \\
\cline { 2 - 5 } & Mean velocity $[\mathrm{m} / \mathrm{s}]$ & 5,599 & 5,598 & 5,517 \\
\cline { 2 - 5 } & Standard deviation $[\mathrm{m} / \mathrm{s}]$ & 4,015 & 4,140 & 4,189 \\
\hline \multirow{4}{*}{$\begin{array}{c}\text { Lelystad } \\
\text { Neg98 }\end{array}$} & $A$ & 5,476 & 5,186 & 5,50 \\
\cline { 2 - 5 } & $k$ & 1,999 & 1,744 & 1,93 \\
\cline { 2 - 5 } & Residual deviation $s_{r}[\%]$ & 0,217 & 0,249 & 0,245 \\
\cline { 2 - 5 } & Mean velocity $[\mathrm{m} / \mathrm{s}]$ & 4,853 & 4,619 & 4,878 \\
\cline { 2 - 5 } & Standard deviation $[\mathrm{m} / \mathrm{s}]$ & 2,538 & 2,733 & 2,633 \\
\hline
\end{tabular}

On analyzing the data, it is possible to say that for wind conditions in the researched locations, all the applied methods gave relatively low values of rest deviations, from 0,199 to 0,249 . It proves wellness of the approximation of researched random variable (wind velocity) distribution function. For the considered approximation techniques in the area of Rymanow, every value of the rest deviations were relatively low and similar. The smallest error was obtained for LSM, which equated to $0,199 \%$ and the highest for MLM $(0,204 \%)$. However, it is possible to observe the difference in given Weibull distribution function parameters evaluations. These differences were about $2,5 \%$ for $A$ parameter and $6,3 \%$ for $k$ parameter, which certainly would be transformed into a differential of wind power density and consequently into given energy amounts. Similarly, for the location of Lelystad, the rest deviations are also low, but the smallest error was obtained for MLM $(0,217 \%)$ and the highest for LSM $(0,249 \%)$. Analysis of the given Weibull distribution function parameters in this case indicates relatively significant differences, equal to $5,7 \%$ for $A$ parameter and $13,2 \%$ for $k$ parameter (in relation to MM, being applied in the "Wind atlas" methodology in program WasP). 


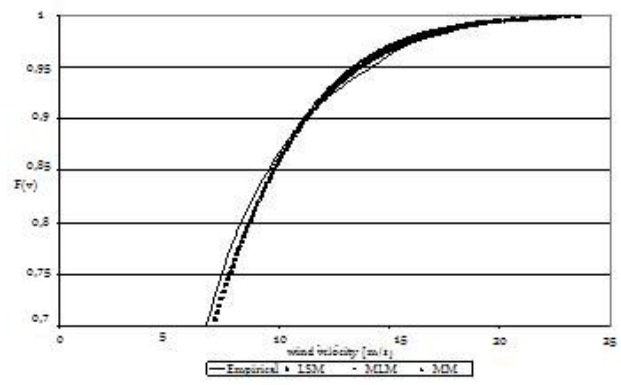

Figure 4: Distribution function curves for wind velocity, given by various approximation methods for the location of Rymanow.

\section{The influence of approximation methods on the quantity of wind energy production}

Wind energy resources may be determined by the application of power density factor $\left(\mathrm{W} / \mathrm{m}^{2}\right)$, which is given by the equation (10) [2,5-7,10-11].

$$
P=\frac{1}{2} \rho \int_{0}^{\infty} v^{3}\left\{\frac{k}{A}\left(\frac{v}{A}\right)^{k-1} \exp \left[-\left(\frac{v}{A}\right)^{k}\right]\right\} d v
$$

where: $k$-shape parameter, $A$-scale parameter.

Table 3: Amounts of power density given on the basis of parameters given by various approximation methods.

\begin{tabular}{|c|c|c|c|c|}
\hline $\begin{array}{c}\text { Data from } \\
\text { location }\end{array}$ & Parameter & MLM & LSM & MM \\
\hline Rymanow & Wind power density $\left[\mathrm{W} / \mathrm{m}^{2}\right]$ & 311 & 324 & 322 \\
\hline Lelystad & Wind power density $\left[\mathrm{W} / \mathrm{m}^{2}\right]$ & 134 & 134 & 141 \\
\hline
\end{tabular}

Source: personal elaboration

On the basis of Weibull distribution function parameters, the wind power density amounts were calculated from equation (10), which are presented in table 3 . It is noticeable that these values differ between themselves. It proves that the method of Weibull distribution function parameters estimation has an influence on the quantity of evaluated wind energy resources. The analysis of occurring differences between wind energy parameters and suitable statistics is presented in table 4 . 
Table 4: $\quad$ Comparison of deviations from real values for mean value, standard deviation and mean wind power density.

\begin{tabular}{|c|c|c|c|c|c|c|c|c|}
\hline \multirow[b]{2}{*}{ Data } & \multirow[b]{2}{*}{ Parameters } & \multirow[b]{2}{*}{$\begin{array}{c}\text { Empirical } \\
\text { data }\end{array}$} & \multicolumn{2}{|c|}{ MLM } & \multicolumn{2}{|c|}{ LSM } & \multicolumn{2}{|r|}{ MM } \\
\hline & & & value & $\begin{array}{c}\text { Deviation } \\
\text { from } \\
\text { value } \\
{[\%]}\end{array}$ & value & $\begin{array}{c}\text { Deviation } \\
\text { from } \\
\text { value } \\
{[\%]}\end{array}$ & value & $\begin{array}{c}\text { Deviation } \\
\text { from } \\
\text { value } \\
{[\%]}\end{array}$ \\
\hline \multirow{3}{*}{$\begin{array}{c}\text { Rymanow } \\
1998 \\
\text { POLAND }\end{array}$} & $\begin{array}{c}\text { Mean } \\
\text { wind velocity }\end{array}$ & 5,591 & 5,599 & 0,14 & 5,598 & 0,13 & 5,517 & $-1,34$ \\
\hline & Variance & 16,655 & 16,120 & $-3,31$ & 17,140 & 2,83 & 17,548 & 5,09 \\
\hline & $\begin{array}{c}\text { Mean } \\
\text { power density }\end{array}$ & 330 & 311 & $-6,11$ & 324 & $-1,85$ & 322 & $-2,48$ \\
\hline \multirow{3}{*}{$\begin{array}{c}\text { Lelystad } \\
1998 \\
\text { NETHERLANDS }\end{array}$} & $\begin{array}{c}\text { Mean } \\
\text { wind velocity }\end{array}$ & 4,850 & 4,853 & 0,06 & 4,619 & $-5,0$ & 4,878 & 0,57 \\
\hline & Variance & 6,472 & 6,441 & $-0,47$ & 7,469 & 13,35 & 6,933 & 6,65 \\
\hline & Mean power density & 138 & 134 & $-2,99$ & 134 & $-2,99$ & 141 & 2,13 \\
\hline
\end{tabular}

The results of this analysis identify the high differential of given parameters by LSM in relation to values given from empirical data. It is mainly visible for the location of Lelystad (5\% for mean value and above $13 \%$ for variance), which may prove the questionable usefulness of this method in analyses concerning wind velocity, and particularly in certain cases (for the location of Rymanow the deviations are acceptable). The rest of the errors for MLM and MM are quite similar, but it is possible to notice some advantage of MLM, for which these deviations (concerning mean value and standard deviation) for both locations are smaller than for MM.

\section{Conclusions}

On the basis of the conducted research and analyses, it is possible to formulate the following conclusions:

1. Weibull distribution function describes correctly the inconsistency of wind velocity, which is proven by very low values of rest deviation.

2. The approximation methods being applied result in slightly different suitability to the empirical data, although the level of rest deviation is similar.

3. The relatively big differential of Weibull distribution function parameters evaluation given by the application of various approximation methods is visible.

4. The evaluations of statistics (mean value and standard deviation) for described techniques also result in a relatively big differential.

5. The amount of wind power density given by the application of researched approximation methods differ between themselves, which proves that the selected method of Weibull parameters estimation influences the values of evaluated wind energy resources. 
6. Relatively high deviations for Weibull distribution function parameters evaluation with application of LSM (location Lelystad) may identify an inherent risk in this method application during analyses concerning wind energy.

7. Deviations for MM and MLM are relatively low and similar, but a certain advantage in MLM is visible, for which these deviations for both locations (concerning mean value and standard deviation) are lower than for MM.

The authors are going to continue and broaden their research, based on a wider array of wind conditions (new locations) and on non-classical methods of distribution function parameters estimation.

\section{Acknowledgement}

The paper is the effect of statutory work no. 11.11.100.276.

\section{References}

[1] Troen I., Petersen E.L., European Wind Atlas, Riso National Laboratory, Roskilde, Denmark, 1989.

[2] Petersen E.L., Mortensen N.G., Landberg L., Hojstrup J., Frank H., Wind Power Meteorology. Riso National Laboratory, Roskilde, Denmark 1997.

[3] Petersen E.L., Troen I., Frandsen S., Hedegaard K., Windatlas for Denmark. A rational method for wind energy siting. Risoe-R-428, Riso National Laboratory, Roskilde, Denmark 1981.

[4] Bowen A.J., Mortensen N.G., Exploring the limits of WAsP program. European Union Wind Energy Conference, 20-24 May, Goteborg, Sweden, 1996.

[5] Soliński B., Wpływ parametrów energetycznych wiatru i elektrownii wiatrowej na wielkość wytworzonej energii elektrycznej. Proceedings of Waste Management School, 15-18 czerwca 2004, Kraków-Rytro, 2004.

[6] Hau E., Wind turbines: fundamentals, technologies, application and economics. Springer Berlin 2000.

[7] Burton T., Sharpe D., Jenkins N., Bossanyi E., Wind Energy Handbook. John Wiley \& Sons Ltd., Chichester 2001.

[8] Soliński I. Soliński B.: Energetyka wiatrowa $w$ Polsce. Wyd. IGSMiE PAN, Kraków,. Polityka Energetyczna, vol.7, iss. 1, 2004.

[9] Albers A., Klug H.: High Quality Wind Speed Measurements for Site Assessment, DEWI Magazine, vol. 15, August, 1999.

[10] Harrison R., Hau E., Snel H., Large wind turbines - design and economics. John Willey \& Sons, Chichester 2000.

[11] Soliński I., Ostrowski J., Soliński B., Energia wiatru. Komputerowy system monitoringu. Wydawnictwa AGH, Kraków 2010.

[12] Parzen E.: On estimation of probability density function and mode, Ann. Math. Statist., vol. 33, 1962. 
[13] Gajek L., Kałuszka M.: Wnioskowanie statystyczne, Warszawa, WNT, 2000.

[14] Koronacki J., Mielniczuk J.: Statystyka dla studentów kierunków technicznych i przyrodniczych, Wyd. Nauk.-Techn., Warszawa, 2001. 